This item was submitted to Loughborough's Research Repository by the author.

Items in Figshare are protected by copyright, with all rights reserved, unless otherwise indicated.

\title{
Residential sorting and environmental externalities: the case of nonlinearities and stigma in aviation noise values
}

PLEASE CITE THE PUBLISHED VERSION

http://dx.doi.org/10.1111/jors.12162

\section{PUBLISHER}

(C) Wiley Periodicals, Inc.

\section{VERSION}

AM (Accepted Manuscript)

\section{PUBLISHER STATEMENT}

This work is made available according to the conditions of the Creative Commons Attribution-NonCommercialNoDerivatives 4.0 International (CC BY-NC-ND 4.0) licence. Full details of this licence are available at: https://creativecommons.org/licenses/by-nc-nd/4.0/

\section{LICENCE}

CC BY-NC-ND 4.0

\section{REPOSITORY RECORD}

Thanos, Sotirios, Abigail L. Bristow, and Mark Wardman. 2019. "Residential Sorting and Environmental Externalities: The Case of Nonlinearities and Stigma in Aviation Noise Values". figshare. https://hdl.handle.net/2134/16661. 


\title{
Residential Sorting and Environmental Externalities: the Case of Non-linearities and Stigma in Aviation Noise Values
}

Sotirios Thanos ${ }^{\mathrm{i}}$, Abigail L. Bristowii, Mark R. Wardman ${ }^{\mathrm{iii}}$.

Forthcoming in the Journal of Regional Science (May 2015 issue)

\begin{abstract}
This paper explores the sorting process in response to differing levels of aviation noise exposure in a housing market. Spatiotemporal Hedonic Pricing (HP) and Stated Choice (SC) results reflect nonlinearities and stigma. The HP models reveal nonlinear noise depreciation increasing from 0.40 to 2.38 percent per decibel as noise increases, while the SC noise values are lower in an area with high long-term noise exposure. These nonlinearities are attributed to the spatial sorting of noise tolerant individuals. HP results from the same "noisy" area show a "stigma" from noise during the first year after the complete removal of aviation noise.
\end{abstract}

Keywords: Valuation of Environmental Effects, Aviation Noise, Sorting, Spatial econometrics, Stigma, Spatio-Temporal Models

JEL classifications: R210, R410, C210, Q510, Q530

Acknowledgements

We would like to thank EUROCONTROL Experimental Centre for funding this research and especially Ted Elliff and Ian Fuller. We also owe thanks to Yiannis Kapanidis for his help with the GIS modeling.

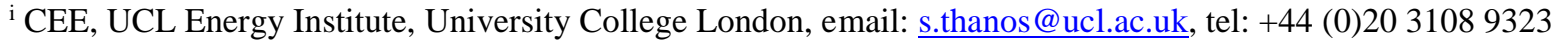

ii School of Civil and Building Engineering, Loughborough University

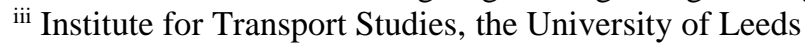




\section{INTRODUCTION}

Sorting ${ }^{1}$ is used in the economics literature as a metaphor for the partition of economic agents across segments of a market, as determined by market forces. With regard to the choice of dwelling location, households sort across neighborhoods in accordance to their preferences for environmental externalities, social attributes, travel costs and budget constraints. Understanding consumer heterogeneity can be especially important for policy relating to public goods and externalities (Kuminoff et al., 2013).

This paper examines sorting in the context of aviation noise. Long term noise exposure can cause health, economic and social problems (Berglund et al., 1999; Miedema, 2007), especially for the 6.9 million people in Europe who are exposed to aviation noise levels above 55 decibels (European Environment Agency, 2010). Examining the issue from an environmental justice angle, Sobbota et al (2007) find socioeconomic attributes such as income, education level and ethnicity to be significant predictors of whether households locate in areas highly exposed to aviation noise, which is consistent with the sorting paradigm. Hence, arriving at robust monetary values for the cost of the aircraft noise externality is important in informing appraisal and policy.

Our theoretical framework is based on the assumption ${ }^{2}$ of preference heterogeneity regarding the level of noise residents are prepared to accept. This creates self-selection pressures that result in a sorting process, whereby few in the housing market are prepared to accept high aircraft noise exposure. This sorting process would over time create pockets of more (and less) noise tolerant consumers across space, reflecting the spatial distribution of aviation noise exposure. We would therefore expect differentiated noise values in different residential areas, according to long-term noise exposure. Hence, we can derive two research hypotheses. First, residents in very "noisy" areas will place lower values on noise nuisance. Second, a higher housing discount is required by new entrants to these areas, as fewer housing market consumers are prepared to accept high aviation noise exposure. A corollary hypothesis is that house buyers and sellers form negative associations for areas exposed to long-term extreme noise; associations that do not immediately dissipate after the removal of noise. These negative associations can result in noise depreciation to house prices or "stigma" that endures for a period after aviation noise has ceased. In this paper we 
test these hypotheses by looking at values of noise depreciation in the housing market derived by Hedonic Pricing (HP) techniques and the direct willingness to pay (WTP) for quietness derived from Stated Choice (SC) exercises.

Identifying the value of aviation noise has traditionally relied upon HP techniques. A common assumption found in the vast majority of HP studies is that of a constant percentage of house price depreciation per decibel of noise, the Noise Depreciation Index (NDI) (Nelson, 2008). There is no theoretical basis for this assumption, only computational convenience, and such an assumption is not consistent with the spatial sorting process of households. A small number of studies (Day et al., 2007; Andersson et al., 2010; Wilhelmsson 2000; Pommerehne, 1988) find progressively higher values per decibel at increasing noise levels, which would be consistent with a sorting process. A closely related issue is that NDI is highly sensitive to the noise threshold ${ }^{3}$ used; with higher the depreciation rates being observed at higher thresholds (Andersson et al. 2010; Cohen and Coughlin, 2008; Bjorner et al., 2003; Rich and Nielsen 2004; Bateman et al., 2001; Lake et al., 1998, 2000) implying a nonlinear relationship, which again is consistent with the spatial sorting process of households.

The behavioural aspect of sorting in relation to transport noise exposure has been explored in Stated Preference ${ }^{4}$ (SP) studies. Arsenio et al. (2006) and Eliasson et al. (2002) found that individuals with higher marginal values of noise tended to live in quieter home locations. Similarly, Wardman and Bristow (2004) found that those who had taken some actions to alleviate noise had higher values of further noise reduction. Conversely, Pommerehne (1988) and Vainio (2001) report that the presence of insulation can reduce the willingness to pay for further noise reduction, which is inconclusive with regard to our hypothesis. A few SP results are not consistent with sorting; according to Faburel and Luchini, (2000) and Thune-Larsen, (1995) noise values are higher for respondents exposed to higher noise levels. However, Thune-Larsen (1995) excluded genuinely noise tolerant individuals, who were not at all annoyed, from the estimation of noise values.

Stigma effects, or the enduring depreciation of housing prices after the removal of a negative externality, have been documented in the literature, in cases of proximity to hazardous 
infrastructure/facilities or criminal activities (Congdon-Hohman, 2013; Hite et al, 2001; McCluskey and Rausser, 2003). However, this effect has not been examined with regard to facilities producing noise externalities.

The research hypotheses are tested by employing data from a rare experimental context, the Hellenikon Airport closure in Athens. First, we test for nonlinearities by the re-estimation of the Thanos et al. (2012) HP model from before the airport closure using a flexible log-sum threshold approach. The novelty of our approach lies in explicitly linking nonlinearities to thresholds in noise valuation and accounting for spatial sorting of households at differing levels of noise exposure. Second, we estimate spatiotemporal HP models for the post airport-closure period to determine whether any stigma from aviation noise remains on house prices. These spatiotemporal models are specified to capture changes in neighborhood quality. These models also address the common misspecification in the literature (Salvi, 2008; Dekkers and Van der Straaten 2009; Chalermpong, 2010; Andersson et al., 2010; Cohen and Caughlin 2008) of treating house sales data as crosssectional and ignoring their temporal dimension. A house sale and its corresponding price are only observed at a specific location and distinct moment in time. The arrow of time and the direction of causality are violated by ignoring this fact with significant econometric shortcomings (Dubé and Legros, 2014; Smith, 2009). To the best of our knowledge this is the first application in the context of noise nuisance examining stigma. Third, as far as we are aware this is the first study to apply SC and HP experiments in the context of aircraft noise removal providing a unique opportunity for a cross method comparison of values. Therefore, we are able to test the research hypotheses from both a revealed and stated preference perspective, looking for noise nuisance values of residents in very "noisy" areas and the housing discount required by new entrants to these areas.

The paper is structured as follows. Section 2 reviews previous evidence on nonlinearities of noise values, threshold selection and stigma. Section 3 explains the log-sum approach to noise threshold setting. Section 4 provides details about the Hellenikon airport closure context, data and studies in the area. Section 5 presents the results of the pre-closure HP models on nonlinearity of aviation noise. The methodological approach, the specification spatiotemporal error models and results of the post-closure HP models are found in Section 6, focusing on stigma. Section 7 brings together 
and discusses the monetary aircraft noise valuation estimates from the SC, HP pre-closure and HP post-closure models. Conclusions are provided in Section 8.

\section{REVIEW OF NONLINEARITY, THRESHOLDS AND STIGMA EVIDENCE}

This section reviews cases of stigma in the housing market and the interconnected issues of nonlinearities and thresholds in noise valuation studies.

\section{Stigma in the housing market}

Stigma effects in the housing market with regard to facilities producing noise externalities have not been documented in the literature, although there are some examples of stigma from other externalities. Congdon-Hohman (2013) looked at the stigma of crime represented by the discovery of a methamphetamine laboratory in the vicinity, using a dataset on house sales in Summit County, Ohio from 2002 to 2009. They found a 10-19 percent decrease in sale prices of houses nearby in the year following a laboratory's discovery compared to those slightly further away, suggesting some persistence of the effect which might be related to a continuing fear of crime. Dale et al. (1999) examined the housing market from 1979 to 1995 around a lead smelter in Dallas that was closed in 1984 and fully cleaned up by 1986. As expected, prices were depressed during the smelter operational period but after the closure they increased across all areas. However, locations closest to the smelter and poorer areas were slower to recover suggesting some continuing effect. McCluskey and Rausser (2003) utilized the same example but allowing the influence of the smelter to decline with distance. They suggest that long-term stigma exists for properties within 1.2 miles of the site. Hite et al. (2001) found that long closed landfill sites in Ohio have small but persistent effect on house prices in the vicinity. Hence, we see examples of stigma effects in the literature having different duration, level of impact and spatial distribution depending on the nature of the effect.

\section{Nonlinearity of noise values and thresholds}

The assumption of constant noise depreciation per decibel has been empirically examined by only a handful of studies. Day et al. (2007) is the only paper to have applied the second stage HP approach in noise valuation and estimated an inverse demand function for road traffic and rail noise. They reported a range of increasing marginal prices for noise corresponding to increasing 
noise levels. The average values for road noise varied appreciably from $£ 31.49$ per annum for a $1 \mathrm{dBA}$ reduction from a $56 \mathrm{dBA}$ baseline to $£ 67.58$ at $71 \mathrm{dBA}$ and $£ 91.15$ at $81 \mathrm{dBA}$. Andersson et al. (2010) specified a model with a pre-imposed nonlinear econometric relationship between house prices and road noise. The model produced a NDI of 1.15 at 50dBA reaching 2.9 at $70 \mathrm{dBA}$.

Wilhelmsson (2000) and Theebe (2004) also arrived at nonlinear NDI estimates, but with a questionable statistical treatment of noise and arbitrary threshold assumptions. Wilhelmsson (2000) uses two different variables for road noise simultaneously in the same model. The first is for all observations having no noise threshold and the second variable includes only houses visually exposed to a major road and a 68dBA threshold, which seems arbitrary after specifying no threshold in the first variable. A nonlinear NDI is calculated combining both variables without appropriate statistical significance tests for $\mathrm{it}^{5}$, even though only the second noise variable is statistically significant. Theebe (2004) produces statistically significant estimates only above $65 \mathrm{dBA}$. The continuous noise data is converted to $5 \mathrm{dBA}$ band dummy variables that make no distinction between observations within a noise contour/band. The noise banding imposes untestable assumptions about functional form of noise depreciation and thresholds.

As already described, a key issue across the noise valuation literature is that of the assumptions used regarding noise thresholds. This is the level below which noise is assumed to impose no nuisance and hence has no monetary value. The absence of cut-off points, as in Brandt and Maenig (2011), is also problematic since it assumes that there is no other sound except the noise source in the model. In HP studies of transport noise the threshold is traditionally set at around 50-55 dBA. Day et al. (2007) used a 55dBA threshold in their first stage HP model. However, further analysis of their second stage results, reported in Nellthorp et al. (2007), suggested that noise values were positive down to a 45dBA threshold. Andersson et al. (2010) specify a semi-logarithmic spatial HP models at two threshold levels of 50 and 55dBA. In their subsequent nonlinear model, they used a 50dBA cut-off and they pre-imposed a concave functional form to this relationship.

There is some divergence in the literature about the significance and selection of noise thresholds that is often treated as a matter of secondary importance. NDI is highly sensitive to the noise threshold used, typically increasing when the threshold is set higher as illustrated in Table 1 where 
we reproduce results from studies using more than one threshold (Andersson et al. 2010; Cohen and Coughlin, 2008; Bjorner et al., 2003; Rich and Nielsen 2002; Bateman et al., 2001 and Lake et al., 1998, 2000).

TABLE 1: Aviation and Road Noise Thresholds employed in recent HP studies

\begin{tabular}{|c|c|c|c|c|}
\hline Authors & Location & Source & $\begin{array}{l}\text { Threshold } \\
\text { dBA }\end{array}$ & NDI \\
\hline $\begin{array}{l}\text { Lake et al. (1998, } \\
2000)\end{array}$ & Glasgow, Scotland & Road & $\begin{array}{l}68 \\
54\end{array}$ & $\begin{array}{l}1.07 \\
0.20\end{array}$ \\
\hline Bjørner et al. (2003) & Copenhagen, Denmark & Road & 55 & 0.47 \\
\hline $\begin{array}{l}\text { Rich and Nielson } \\
(2004)\end{array}$ & Copenhagen, Denmark & Road & 50 & $\begin{array}{l}\text { Houses: } 0.54 \\
\text { Flats: } 0.47\end{array}$ \\
\hline Bateman et al. (2004) & Birmingham, England & Road & 55 & $0.21-0.53$ \\
\hline Theebe (2004) & Western Netherlands & $\begin{array}{l}\text { Combined } \\
\text { transport } \\
\text { noise } \\
\end{array}$ & $\begin{array}{l}65 \\
\text { dummy } \\
\text { specification }\end{array}$ & 0.3 to 0.5 \\
\hline $\begin{array}{l}\text { Baranzini and } \\
\text { Ramirez (2005) }\end{array}$ & $\begin{array}{l}\text { Geneva, Switzerland, rental } \\
\text { sector }\end{array}$ & Road & 50 & 0.25 \\
\hline Salvi (2008) & Zurich, Switzerland & $\begin{array}{l}\text { Road } \\
\text { Aviation }\end{array}$ & $\begin{array}{l}50 \\
50\end{array}$ & $\begin{array}{l}0.82 \\
0.97\end{array}$ \\
\hline $\begin{array}{l}\text { Cohen and Coughlin } \\
(2008)\end{array}$ & Atlanta, US & Aviation & $\begin{array}{l}65 \text { dummy } \\
70 \text { dummy }\end{array}$ & $\begin{array}{l}\mathrm{NSS}^{\mathrm{a}} \\
3.3 \\
\end{array}$ \\
\hline $\begin{array}{l}\text { Dekkers and Van der } \\
\text { Straaten (2009) }\end{array}$ & Amsterdam, Netherlands & $\begin{array}{l}\text { Road } \\
\text { Aviation } \\
\text { Aviation } \\
\end{array}$ & $\begin{array}{l}55 \\
45 \\
48 \\
\end{array}$ & $\begin{array}{l}0.14 \\
0.80 \\
0.50 \\
\end{array}$ \\
\hline $\begin{array}{l}\text { Andersson et al. } \\
(2010)\end{array}$ & Lerum, Sweden & Road & $\begin{array}{l}50 \\
55 \\
\end{array}$ & $\begin{array}{l}1.15 \\
1.69\end{array}$ \\
\hline $\begin{array}{l}\text { Brandt and Maenig } \\
(2011)\end{array}$ & Hamburg, Germany & $\begin{array}{l}\text { Road } \\
\text { Aviation }\end{array}$ & $\begin{array}{l}\text { None } \\
62\end{array}$ & $\begin{array}{l}0.23 \\
0.13\end{array}$ \\
\hline Thanos et al. (2012) & Athens, Greece & Aviation & 55 & 0.49 \\
\hline
\end{tabular}

aSS: not statistically significant at $95 \%$

The only exception to this is the Dekkers and Van der Straaten (2009) study, where higher thresholds reduced the aircraft noise depreciation and oddly the coefficient becomes insignificant at a 50dBA threshold. They report a model with thresholds that vary by the noise source; $45 \mathrm{dBA}$ for air traffic, 55dBA for road and 60dBA for rail. While the use of different thresholds attempts to reflect evidence in the noise annoyance literature, it is questionable in this context. They are effectively assuming that road traffic noise will not impact on welfare until it is 55dBA, whereas aircraft noise will do so at half the intensity, $45 \mathrm{dBA}$. 
The threshold levels set for a single noise source should take account of the acoustic environment. Bjørner et al. (2003) cautioned that their identification of 55dBA as threshold was for a large urban area and that a lower level may be appropriate in a more rural environment. Similarly, Thanos et al. (2011) found that a threshold of 55dBA gave the best fit to the urban area data but that a lower threshold of $47 \mathrm{dBA}$ produced a better fit to data in more rural areas. Evidence from other SP studies is sparse. Weinberger (1992) used a low cut off at 40dBA in a Contingent Valuation study in Germany. Bristow and Wardman (2006) found that the model fit deteriorated if a threshold was imposed, using aircraft valuation SC data from Lyon and Manchester. Although limited, such SP evidence as there is appears to suggest lower or no thresholds than those usually applied in HP.

While monetary noise values in HP are sensitive to thresholds, their selection is often arbitrary and usually not tested. The threshold issue is closely connected to the hypothesis of nonlinear noise depreciation: the higher the threshold the higher the NDI. We address this methodological issue in Section 3, introducing the specification of a flexible log-sum threshold found in Thanos et al., (2011, 2012), which also explicitly includes background noise levels.

\section{THE LOG-SUM NOISE THRESHOLD APPROACH}

The physical characteristics/properties of noise are important in the analysis and threshold specification. Noise data are comprised of statistical indicators summarizing sound pressure levels

over time at the logarithmic scale of decibel $(\mathrm{dB})$ units and a frequency weighting, " $\mathrm{A}$ " in this case $^{6}$ (Berglund et al., 1999). Transportation noise data, used in HP, are usually derived from traffic flows (of trains, airplanes or road vehicles) through noise models, as taking actual noise measurements over long periods of time in hundreds or thousands of locations would be impractical. Hence, the available noise data often refer to specific noise sources and the average overall noise levels for a large area might also be approximated.

Let us take the simplest case, where data are available for a specific noise source, say aviation $\gamma_{\mathrm{a}}$. The overall noise level $\gamma_{\mathrm{b}}$ from all other sources except aviation, henceforth termed background noise, is also known. The issue with typical thresholds/cut-off points for a specific noise source is that the noise variation in cross-sectional data is reduced as the threshold increases for that source. This is because any observation below the threshold is assumed to be equal to the cut-off point. 
For aviation noise, most of the observations in an affected area will exceed a 45dBA cut-off point, but very few will exceed a $75 \mathrm{dBA}$ cut-off. This lack of variation at higher cut-off points (e.g. over $75 \mathrm{dBA}$ ) causes the noise coefficients in HP models to be statistically insignificant in any given dataset.

In HP models we want to capture the effect of aviation noise on the housing market above the general noise level in the area, even for lower aviation noise levels, which is not possible with typical cut-off points. Therefore, we follow Thanos et al. $(2011,2012)$ to define a total noise level $\left(\gamma_{t}\right)$, given by the combination of aviation noise level $\left(\gamma_{a}\right)$ and the background noise level $\left(\gamma_{b}\right)$, as:

$$
\gamma_{\mathrm{t}}\left(\gamma_{\mathrm{a}}, \gamma_{\mathrm{b}}\right)=10 \log _{10}\left(10^{\gamma_{\mathrm{a}} / 10}+10^{\gamma_{\mathrm{b}} / 10}\right)
$$

If $\gamma_{\mathrm{a}}$ is dominant, $\gamma_{\mathrm{b}}$ will have an almost negligible effect on the total noise level and vice versa. Equation 1 is commonly employed in the acoustics literature to calculate the sum of sound levels from different sources (see Genescà et al., 2013). This has been completely overlooked in the economics literature that addresses noise valuation, with the exception of Andersson et al. (2010). However, they used Equation 1 to combine just rail and road noise levels to a "total" noise level, and subsequently employed a typical cut-off point for the "total" noise level.

The threshold specification provided in Equation 1 has the advantage of including in the analysis even low levels of aircraft noise that would otherwise have been below a certain cut off point. Hence, by including all observations the log-sum thresholds do not reduce noise variation in crosssectional data, as typical cut-off points do. Furthermore, we take advantage of this property of logsum thresholds to examine nonlinearities, by determining the depreciation of house prices due to aircraft noise for a range of thresholds between $45-75 \mathrm{dBA}$. This is reported in Section 5.

\section{THE AIRPORT CLOSURE CONTEXT AND DATA}

Athens International Airport (AIA) or Hellenikon Airport operated for more than 40 years in the southern suburbs of Athens, Greece. In March 2001, it was closed and the main Airport hub was moved to the northeast of Athens. The population of the wider area affected at the airport by the time of its closure was over 350,000, with a significant variation of aircraft noise exposure. The following data types and approaches relevant to this context are presented here: aviation noise 
data, the SC data and approach, the HP approach before the airport closure and housing data for the post-closure period.

\section{Aircraft noise data for Hellenikon Airport}

The aircraft noise data for Hellenikon airport were supplied by the European Organization for the Safety of Air Navigation (EUROCONTROL), who have complete data on flight paths and aircraft movements for Hellenikon Airport. The consistency of the modelled data with actual noise measurements was confirmed by EUROCONTROL. A set of coordinates for each house sale or interview location was provided to EUROCONTROL and they supplied an estimate of its aircraft noise exposure.

Thanos et al. $(2011,2012)$ employed the $\mathrm{L}_{\mathrm{den}}{ }^{7}$ noise metric, which is seen as appropriate for aircraft noise in the EU (EC, 2002) and is commonly used in studies valuing noise (Dekkers and Van der Straaten, 2009; Rich and Nielsen, 2004; Baranzini and Ramirez, 2005). Miedema et al. (2000) investigated which noise metrics best predict annoyance from aircraft noise and supported the use of weighted noise metrics, such as $\mathrm{L}_{\mathrm{den}}$, instead of $\mathrm{L}_{\mathrm{eq}}$ in this context.

Unfortunately, no data were available on other sources of noise pollution such as road traffic. We follow Thanos et al. $(2011,2012)$ who set a 55dBA value for background noise $\gamma_{b}$, deduced from previous studies of the noise situation in Athens that do not address aircraft noise (Nicol and Wilson, 2004; Yang and Kang, 2005), and used the $\gamma_{t}$ in Equation1 for aircraft noise in the HP and SC models. In the SC experiment, the absence of aircraft noise is simply the background noise level $\gamma_{\mathrm{b}}$ (Thanos et al., 2011).

\section{$\underline{\mathrm{SC} \text { around Hellenikon airport }}$}

The SC experiment of Thanos et al. (2011) had a highly innovative basis in respondents' experienced changes of aircraft noise after its total removal due to the Hellenikon airport closure or its onset around the new airport. Respondents' perceptions of noise change were directly linked to changes in decibels, replacing the aircraft-noise/no-aircraft-noise variable with the aircraft noise exposure at the location of each interview. The SC experiments were conducted in 2005 and yielded 700 questionnaires and 5600 observations, of which 468 questionnaires and 3744 
observations were for the areas around Hellenikon Airport. The SC experiments around Hellenikon were conducted in a subset ${ }^{8}$ of the case study area of the Thanos et al. (2012).

Table 2 presents the relevant monetary aircraft noise estimates of WTP and willingness to accept compensation (WTA) from Thanos et al. (2011). WTP and WTA were calculated by dividing the aviation noise coefficient by the cost coefficients for "local tax" increases and reductions respectively. WTP and WTA here are different consumer surplus measures, equivalent loss and compensating loss respectively (Bateman et al, 2000), which partly explains their difference. The potential loss aversion of respondents may also contribute to this by affecting WTA (Tversky and Kahneman, 1991).

The Alimos area was exposed to significantly higher aircraft noise than any other location surveyed. This is further supported by Yang and Kang (2005) who found Alimos to be the noisiest residential neighborhood in a study of 14 urban areas in Europe. However, the WTP and WTA values for Alimos are far lower, nearly a tenth of those for other areas. Thanos et al. (2011) suggested a sorting process of noise tolerant residents in this area as an explanation for this result, given several decades of high noise exposure in Alimos (Charalampakis, 1980). Hence, there is scope to examine the variation of HP monetary values in Alimos and compare with these results.

TABLE 2: WTP and WTA Values for Aircraft Noise at Hellenikon Airport from a Stated Choice Experiment

\begin{tabular}{lrr}
\hline WTP $€ /$ hh $/$ month & WTA $€ / \mathrm{hh} /$ month \\
\hline Other areas & $1.14^{* *}$ & $6.96^{*}$ \\
Alimos & $0.14^{* *}$ & $0.84^{*}$ \\
$* * *$ significant at $\mathrm{p}<0.01 ; * *$ & significant at $\mathrm{p}<0.05 ; *$ s significant at $\mathrm{p}<0.10$
\end{tabular}

Source: Thanos et al. (2011)

Pre-closure HP analysis and results

Thanos et al. (2012) applied spatiotemporal HP models on 1613 house sales from 1995 to 2001, while Hellenikon airport was operational. Their novel specification of spatiotemporal HP models is further discussed in section 6 . They obtained statistically significant coefficients for aircraft noise and an NDI estimate of 0.493 . 


\section{$\underline{\text { Post-closure Housing Data }}$}

This study employs 773 observations of house sales starting immediately after the Hellenikon airport closure on the 2nd quarter of 2001 to the end of 2003. Table 3 presents the data including information about the basic structural characteristics of each house, such as the square meters of floor space, construction year, sale date, number of rooms, presence of a garage, floor number and house type. The full address of each house sale allowed the use of GIS to estimate additional geographical information. Frankel (1988) and Bateman et al. (2001) found local amenities to influence house prices. A number of amenity locations were acquired and the straight distance between each house and the nearest school, city square, public service facility, and park/sportfacility was calculated.

The distance from each house to the airport was also estimated. Even though there is no longer an airport, there may still be disamenities from an abandoned airport or amenities as there were plans to convert part of the site to a park and it housed many venues for the 2004 Olympic Games. It is noted that due to the geography of the area (see Fig. 2, Thanos et al 2012) the spatial variation of noise does not coincide with distance to the airport in our data (correlation coefficient: 0.033 ). As the housing data here is for the post airport closure period, there is no aircraft noise in the area around the old airport. Therefore, to test for any remaining stigma from aircraft noise, we employ noise data from the last year of Hellenikon Airport operation in 2000.

As expected, Alimos exhibits significantly higher aircraft noise levels compared to the other study areas in Table 3. We create two interaction variables between aircraft noise and Alimos area to capture noise effects specific to this area. The first (Noise_Alimos) contains the total noise level $\left(\gamma_{t}\right)$ of house sales only in Alimos, keeping all other house sales at the background noise $\left(\gamma_{b}\right)$ level of 55dBA. The second (Noise_No_Alimos) is the reverse, containing only the background noise $\left(\gamma_{\mathrm{b}}\right)$ for Alimos house sales and the total noise level including aircraft $\left(\gamma_{\mathrm{t}}\right)$ for all other areas. 
TABLE 3: Post-Closure Data description

\begin{tabular}{|c|c|c|c|c|c|}
\hline Variable & Description & Mean & S.D. & Min & Max \\
\hline price & $\begin{array}{l}\text { Mean house sale price in } € \text { in } 2003 \\
\text { levels }\end{array}$ & 252034 & 181603 & 50201 & 1235814 \\
\hline Ln_price & Natural Logarithm of the house price & 12.24 & 0.61 & 11 & 14 \\
\hline room_no & Number of rooms & 3.73 & 1.31 & 1 & 9 \\
\hline built_per & $\begin{array}{l}\text { Time elapsed in years since } \\
\text { construction of building }\end{array}$ & 3.22 & 2.83 & 1 & 18 \\
\hline floor_no & floor number & 2.12 & 1.51 & 0 & 7 \\
\hline Aviation_noise & dBA Lden of aviation noise & 62.36 & 7.02 & 45.3 & 83.6 \\
\hline Total_noise & $\begin{array}{l}\text { The log-sum of aircraft }\left(\mathrm{dBA} \mathrm{L}_{\mathrm{den}}\right) \text { and } \\
\text { background (55dBA) noise }\end{array}$ & 63.84 & 5.56 & 55 & 84 \\
\hline Noise_Alimos & As above only for Alimos area & 67.27 & 6.12 & 56 & 82 \\
\hline $\begin{array}{l}\text { Noise_No_Ali } \\
\text { mos }\end{array}$ & As above for all areas except Alimos & 62.90 & 5.01 & 55 & 84 \\
\hline sq meters & Square meters of the house floor & 94.37 & 58.51 & 21 & 470 \\
\hline room1_2 & Dummy equals 1 when 1 or 2 rooms & 0.17 & 0.37 & 0 & 1 \\
\hline room3 & Dummy equals 1 when 3 rooms & 0.25 & 0.43 & 0 & 1 \\
\hline room4 & Dummy equals 1 when 4 rooms & 0.39 & 0.49 & 0 & 1 \\
\hline room5 & Dummy equals 1 when 5 rooms & 0.06 & 0.23 & 0 & 1 \\
\hline room6 & Dummy equals 1 when 6 rooms & 0.05 & 0.23 & 0 & 1 \\
\hline room7 & Dummy equals 1 when 7 rooms or over & 0.05 & 0.22 & 0 & 1 \\
\hline House $>10 \mathrm{yr}$ & $\begin{array}{l}\text { Dummy equals } 1 \text { when house built over } \\
\text { 10years }\end{array}$ & 0.06 & 0.23 & 0 & 1 \\
\hline House 6-9yr & $\begin{array}{l}\text { Dummy equals } 1 \text { when house built } \\
\text { between } 6 \text { and } 9 \text { years ago }\end{array}$ & 0.08 & 0.28 & 0 & 1 \\
\hline H_Age_B & $\begin{array}{l}\text { Dummy equals } 1 \text { when the house age is } \\
\text { below } 5 \text { years or unknown }\end{array}$ & 0.86 & 1.00 & 0 & 1 \\
\hline floors_7-8 & Dummy equals 1 when floor num. 7-8 & 0.00 & 0.06 & 0 & 1 \\
\hline floors_4-6 & Dummy equals 1 when floor num. 4- 6 & 0.18 & 0.39 & 0 & 1 \\
\hline floors $<4$ & $\begin{array}{l}\text { Dummy equals } 1 \text { when floor number is } \\
\text { below } 4 \text { or unknown }\end{array}$ & 0.82 & 0.97 & 0 & 1 \\
\hline detached & Dummy equals 1 when detached house & 0.04 & 0.19 & 0 & 1 \\
\hline Semi_ter & $\begin{array}{l}\text { Dummy equals } 1 \text { when semidetached or } \\
\text { terraced house }\end{array}$ & 0.04 & 0.20 & 0 & 1 \\
\hline Flat & Dummy equals 1 when flat & 0.92 & 1.94 & 0 & 1 \\
\hline garage & Dummy equals 1 when private garage & 0.30 & 0.46 & 0 & 1 \\
\hline d_parks & $\begin{array}{l}\text { Distance in meters to the nearest park or } \\
\text { outdoor sporting facility }\end{array}$ & 576 & 335 & 21 & 1676 \\
\hline d_public_serv & $\begin{array}{l}\text { Distance in meters to the nearest public } \\
\text { service building }\end{array}$ & 540 & 333 & 14 & 1865 \\
\hline d_plaza & Distance in meters to the nearest plaza & 360 & 207 & 14 & 1168 \\
\hline d_school & Distance in meters to the nearest school & 368 & 254 & 14 & 1699 \\
\hline d_airport & Distance in meters to the airport & 5061 & 2454 & 497 & 10760 \\
\hline y2001-y2003 & Dummies for each year from 2001 to 2003 & & & & \\
\hline
\end{tabular}




\section{NONLINEARITY OF THE NDI}

As discussed in Section 3, the log-sum threshold specification in Equation1 does not reduce noise variation at higher noise levels as much as typical cut-off points do. We exploit this property to examine nonlinearities by determining the depreciation of house prices due to aircraft noise that exceeds a range of thresholds from $45 \mathrm{dBA}$ to $75 \mathrm{dBA}$.

The aircraft noise data used in Thanos et al. (2012) is appropriate for this exercise as it exhibits a wide noise variation. We exactly replicate the preferred HP model of Thanos et al. (2012), diverging only in the aircraft noise variable specification. The model with a $55 \mathrm{dBA}$ threshold, which is considered the average background value for all the areas around the old airport, is identical to that reported in Thanos et al. (2012).

An iterative process was adopted by varying the threshold value $\left(\gamma_{b}\right)$ in equation 1 from 45 to 75 $\mathrm{dBA}$ and estimating separate HP model for each threshold value $\left(\gamma_{\mathrm{b}}\right)$ and resulting total noise level $\left(\gamma_{\mathrm{t}}\right)$. This should be looked at as filtering process, consistent with sorting, that is dominated by the aviation noise $\left(\gamma_{\mathrm{a}}\right)$ values that exceed each threshold $\left(\gamma_{\mathrm{b}}\right)$ level. It is noted that aviation noise $\left(\gamma_{\mathrm{a}}\right)$ varies from $38-82 \mathrm{dBA}$. The results from the log-sum threshold specification are compared to results by identical models that employ the typical cut-off points.

Table 4 presents the NDI estimates from our iterative modelling process. Our preferred results correspond with the relationship previously assumed by Andersson et al. (2010); the relationship identified between noise exposure and house prices is indeed concave, as the NDI increases convexly (see Figure 1). A one dBA increase in noise levels would cause house prices to fall by 0.4 percent at $45 \mathrm{dBA}$ but by 2.38 percent at $75 \mathrm{dBA}$. The rate increases slowly until the noise level reaches around $65 \mathrm{dBA}$ when the rate of increase becomes more rapid. This nonlinearity is consistent with the sorting; new buyers require discounts that increase nonlinearly in progressively noisier locations.

Looking at the final log-likelihood, the overall fit to the data is reduced with increasing thresholds in both specifications. This is expected as essentially each model is placing increasing constraints on the data, thus reducing noise variation. It is stressed that this not an exclusive characteristic to 
our data, it is an inherent property of the estimation. Data from other studies would produce similar results when estimating models with different cut-off thresholds, as in Dekkers and Van der Straaten (2009) study higher cut-offs reduced the statistical significance of noise aircraft noise depreciation, losing significance at 50dBA.

TABLE 4: Comparison of pre-closure HP results with Log-sum and Typical Cut-off Thresholds

\begin{tabular}{|c|c|c|c|c|c|c|c|c|c|c|}
\hline \multirow{2}{*}{$\begin{array}{l}\text { Threshold Level } \\
\mathrm{dBA}_{\text {Lden }}\end{array}$} & \multicolumn{5}{|c|}{ HP results with log-sum thresholds } & \multicolumn{5}{|c|}{ HP results with typical cut-off point thresholds } \\
\hline & $\mathrm{NDI}$ & $\mathrm{z}^{\mathrm{a}}$ & NDI 95\% & onf. Int. & Final LL & $\mathrm{NDI}$ & $\mathrm{z}^{\mathrm{a}}$ & NDI 95\% & Conf. Int. & Final LL \\
\hline 45 & 0.4025 & -3.64 & 0.6194 & 0.1856 & 235.73 & 0.3823 & -3.60 & 0.5905 & 0.1740 & 235.81 \\
\hline 46 & 0.4069 & -3.64 & 0.6261 & 0.1877 & 235.67 & 0.3853 & -3.60 & 0.5951 & 0.1754 & 235.78 \\
\hline 47 & 0.4120 & -3.64 & 0.6339 & 0.1901 & 235.61 & 0.3883 & -3.60 & 0.6000 & 0.1766 & 235.73 \\
\hline 48 & 0.4181 & -3.64 & 0.6430 & 0.1932 & 235.54 & 0.3908 & -3.59 & 0.6044 & 0.1772 & 235.66 \\
\hline 49 & 0.4248 & -3.64 & 0.6532 & 0.1963 & 235.45 & 0.3936 & -3.58 & 0.6092 & 0.1780 & 235.59 \\
\hline 50 & 0.4327 & -3.65 & 0.6651 & 0.2002 & 235.36 & 0.3969 & -3.57 & 0.6148 & 0.1790 & 235.51 \\
\hline 51 & 0.4418 & -3.65 & 0.6789 & 0.2047 & 235.26 & 0.4035 & -3.59 & 0.6239 & 0.1830 & 235.50 \\
\hline 52 & 0.4521 & -3.66 & 0.6945 & 0.2097 & 235.14 & 0.4101 & -3.60 & 0.6331 & 0.1871 & 235.48 \\
\hline 53 & 0.4639 & -3.66 & 0.7125 & 0.2154 & 235.01 & 0.4131 & -3.59 & 0.6390 & 0.1873 & 235.31 \\
\hline 54 & 0.4777 & -3.66 & 0.7333 & 0.2220 & 234.87 & 0.4151 & -3.54 & 0.6446 & 0.1856 & 235.03 \\
\hline 55 & 0.4932 & -3.66 & 0.7570 & 0.2293 & 234.70 & 0.4175 & -3.49 & 0.6521 & 0.1829 & 234.65 \\
\hline 56 & 0.5110 & -3.67 & 0.7843 & 0.2378 & 234.52 & 0.4272 & -3.47 & 0.6686 & 0.1858 & 234.36 \\
\hline 57 & 0.5317 & -3.67 & 0.8159 & 0.2474 & 234.33 & 0.4411 & -3.46 & 0.6907 & 0.1915 & 234.08 \\
\hline 58 & 0.5557 & -3.67 & 0.8526 & 0.2587 & 234.13 & 0.4554 & -3.45 & 0.7144 & 0.1964 & 233.74 \\
\hline 59 & 0.5826 & -3.66 & 0.8943 & 0.2709 & 233.90 & 0.4719 & -3.42 & 0.7421 & 0.2018 & 233.34 \\
\hline 60 & 0.6137 & -3.66 & 0.9425 & 0.2848 & 233.65 & 0.4935 & -3.40 & 0.7782 & 0.2088 & 232.94 \\
\hline 61 & 0.6492 & -3.65 & 0.9980 & 0.3004 & 233.39 & 0.5284 & -3.40 & 0.8330 & 0.2238 & 232.66 \\
\hline 62 & 0.6898 & -3.63 & 1.0619 & 0.3177 & 233.11 & 0.5742 & -3.40 & 0.9050 & 0.2434 & 232.39 \\
\hline 63 & 0.7359 & -3.61 & 1.1351 & 0.3368 & 232.82 & 0.6239 & -3.36 & 0.9879 & 0.2600 & 231.95 \\
\hline 64 & 0.7898 & -3.59 & 1.2207 & 0.3589 & 232.52 & 0.6786 & -3.30 & 1.0819 & 0.2753 & 231.41 \\
\hline 65 & 0.8498 & -3.56 & 1.3178 & 0.3818 & 232.18 & 0.6978 & -3.05 & 1.1464 & 0.2492 & 230.26 \\
\hline 66 & 0.9197 & -3.52 & 1.4314 & 0.4080 & 231.85 & 0.6969 & -2.72 & 1.1995 & 0.1943 & 228.98 \\
\hline 67 & 0.9982 & -3.47 & 1.5613 & 0.4352 & 231.49 & 0.6948 & -2.39 & 1.2642 & 0.1253 & 227.86 \\
\hline 68 & 1.0896 & -3.42 & 1.7134 & 0.4657 & 231.13 & 0.7211 & -2.16 & 1.3755 & 0.0666 & 227.10 \\
\hline 69 & 1.1949 & -3.36 & 1.8910 & 0.4988 & 230.76 & 0.7775 & -2.00 & 1.5399 & 0.0152 & 226.59 \\
\hline 70 & 1.3178 & -3.30 & 2.0998 & 0.5357 & 230.40 & 0.8319 & -1.79 & 1.7410 & -0.0772 & 226.06 \\
\hline 71 & 1.4645 & -3.24 & 2.3498 & 0.5791 & 230.07 & 0.7878 & -1.38 & 1.9051 & -0.3296 & 225.31 \\
\hline 72 & 1.6362 & -3.18 & 2.6458 & 0.6266 & 229.74 & 0.6035 & -0.84 & 2.0156 & -0.8087 & 224.62 \\
\hline 73 & 1.8377 & -3.10 & 2.9976 & 0.6777 & 229.40 & 0.7284 & -0.77 & 2.5768 & -1.1200 & 224.50 \\
\hline 74 & 2.0830 & -3.04 & 3.4261 & 0.7399 & 229.11 & 1.0164 & -0.79 & 3.5232 & -1.4904 & 224.46 \\
\hline 75 & 2.3791 & -2.98 & 3.9453 & 0.8129 & 228.84 & 1.5391 & -0.84 & 5.1169 & -2.0387 & 224.46 \\
\hline
\end{tabular}

${ }^{\mathrm{a}}$ The $\mathrm{z}$ value refer to the coefficients in the regression 
The comparison between the log-sum threshold and a typical cut-off specification is quite interesting, clearly demonstrating the superiority of the log-sum threshold approach. The difference between the two specifications to overall goodness of fit is trivial at lower noise levels, but markedly increases in favor of the log-sum specification especially above 65dBA. The NDIs from the log-sum threshold models have higher statistical significance across the whole range of thresholds. As expected, NDI from the typical cut-off specification increase with increasing thresholds and is closer to the NDI values from log-sum specification at lower thresholds. At higher threshold levels, especially above 50dBA, this difference becomes more pronounced. At the same time, the cut-off model NDIs become more "noisy" and at $67 \mathrm{dBA}$ and 70dBA lose statistical significance at the 99 and 95 percent level respectively. The NDI significance in log-sum threshold model is highest at 56-58dBA, compared to 45-47 dBA in the cut-off threshold models.

These issues amply demonstrate the weakness of the typical cut-off specification, especially at higher noise levels. In principle, the log-sum threshold approach could be extended to combine noise from multiple noise sources and account for the general soundscape (and even introduce variation across areas) in a more realistic manner to typical cut-off points where such data is available.

\section{STIGMA}

Having established nonlinearities in house price depreciation from aircraft noise, the next step is to determine whether any stigma remains after the removal of the noise externality. Furthermore, we can also examine whether nonlinearity is an issue here as well. We have therefore estimated models with housing data in the post-closure period to examine the stigma hypothesis from aircraft noise and any nonlinearities.

\section{Methodology and Spatiotemporal Considerations}

HP posits that the price of a composite commodity, housing in this case, is a function of its utility bearing attributes. The slope of the HP function can be used to determine the consumer's WTP for a given attribute, such as noise. A house sale and its corresponding price are only observed at $a$ specific location and distinct moment in time. Henceforth, the house sale data are called spatiotemporal data and it is stressed that this is not panel data nor cross-sectional. 
Indeed, subjecting spatiotemporal data to the "cross-sectional" treatment and ignoring the temporal dimension is the common approach in recent spatial econometric HP papers that value noise (Salvi, 2008; Dekkers and Van der Straaten 2009; Chalermpong, 2010; Andersson et al., 2010; Cohen and Caughlin 2008). This misspecification produces a symmetric spatial weight matrix $\mathbf{S}$, given in equation 2 ,

$$
\mathrm{s}_{i j}=\left\{\begin{array}{ll}
f\left(\mathrm{~d}_{i j}\right) & \text { if } i \neq j \\
0 & \text { if } i=j
\end{array},\right.
$$

where house sales/prices simultaneously influence each other weighted by a function of distance $d$. Hence, future sales/prices are taken to influence past sale/prices, which violates the laws of physics. House prices are time-variant and information about future prices cannot possibly travel backwards in time, hence Spatial Autoregressive (SAR) models ${ }^{9}$ are not appropriate for spatiotemporal data. Furthermore, future house prices cannot and should not be taken as proxies of current expectations for the future, as current expectations are only shaped by information in the present/past, amply demonstrated by the recent housing crisis.

The following argument for the Spatial Error Model (SEM) application to spatiotemporal data has been put forward: SEM is supposed to be capturing time-invariant spatially distributed errors affecting the $\mathrm{IID}^{10}$ properties of the regression residuals. Nevertheless, it makes no sense to use the symmetric spatial weight matrix to account for time-invariant spatial errors in spatiotemporal data. A spatially weighted error term in HP only captures spatially distributed unobserved effects specifically from other house sales. Therefore, unobserved effects of house sales in the future cannot affect house prices in the past. Time-invariant unobserved effects influence both past and future in the same way. Hence, these time-invariant effects should not be accounted for by spatially weighting HP residuals of house sales that have not happened yet, but by an additional separate time-invariant error term. This is a significant avenue for future research (Smith and Wu, 2009), but beyond the scope of this paper.

Imposing a "cross-sectional" treatment to spatiotemporal data produces an over-connected spatial weight matrix, in which all observations simultaneously influence each other. Smith (2009) demonstrated that the presence of strongly connected spatial weight matrices introduces serious 
biases into both the testing and estimating of spatial dependence. These biases have been found to erroneously subsume coefficient estimates of genuinely exogenous effects (Dubé and Legros, 2014; Thanos et al., 2012; Bateman et al. 2004). The effects of overlooking or miss-representing the temporal dimension of spatiotemporal data is the focus of an emerging body of spatial econometrics literature (Smith and Wu, 2009; Nappi-Choulet and Maury, 2009, 2011; Huang et al., 2010; Dubé and Legros, 2013a, 2013b, 2014; Dubé et al., 2014; Thanos et al., 2012).

We adopt the approach of Thanos et al. (2012), also followed in the pre-closure models. The spatiotemporal weight matrix $\mathbf{W}$ is specified to include both spatial and temporal distance. Each element in matrix $\mathbf{W}$ is the product of the spatial $s_{i j}$ and temporal $t_{i j}$ distance between each pair of observations (house sales), as given respectively in equation 3:

$$
s_{i j}= \begin{cases}d_{i j}^{-1} & \forall \tau_{\mathrm{i}}>\tau_{\mathrm{j}} \wedge \mathrm{i} \neq \mathrm{j} \\ 1 & \forall d_{i j}=0 \wedge \mathrm{i} \neq \mathrm{j} \\ 0 & \forall \tau_{\mathrm{i}} \preccurlyeq \tau_{\mathrm{j}} \vee \mathrm{i}=\mathrm{j}\end{cases}
$$

and equation 4:

$$
t_{i j}=\left\{\begin{array}{cc}
\left(\xi_{\mathrm{i}}-\xi_{\mathrm{j}}\right)^{-1} & \forall\left(\xi_{\mathrm{i}}-\xi_{\mathrm{j}}\right)>0 \wedge \mathrm{i} \neq \mathrm{j} \\
1 & \forall \xi_{\mathrm{i}}=\xi_{\mathrm{j}} \wedge \mathrm{i} \neq \mathrm{j} \\
0 & \forall\left(\xi_{\mathrm{i}}-\xi_{\mathrm{j}}\right)<0 \vee \mathrm{i}=\mathrm{j}
\end{array} .\right.
$$

$d_{i j}$ is simply the Euclidean distance between $i$ and $j . \tau_{\mathrm{i}}$ and $\tau_{\mathrm{j}}$ are the sale dates of houses $i$ and $j$ respectively. The spatial distance effects are only included in $\mathbf{W}$ when the sale of house $i$ succeeds the sale of house $j$. When the data are ordered chronologically, $\mathbf{W}$ is a lower triangular matrix. Only sales in the past affect subsequent sales and not vice versa. $\xi$ is an appropriate time metric, quarter in this case (see Thanos et al. 2012), starting at the earliest observation in the data. Hence, $\xi_{\mathrm{i}}-\xi_{\mathrm{j}}$ captures the time elapsed between the observations $i$ and $j$.

SAR and SEM are transformed to Spatiotemporal Autoregressive (STAR) model and Spatiotemporal Error Model (STEM) respectively, given that spatiotemporal instead of spatial weight matrices are employed. The differences also extend to how the coefficients of the spatiotemporal effects are interpreted. STAR captures unidirectional spatial spillovers only from 
past observations, instead of the multidirectional endogenous effects in SAR. STAR can include technological and/or pecuniary spillovers, but the spatial multiplier discussed in Small and Steimetz (2012) is not applicable here, since the spillovers are unidirectional.

The STEM specification applied house sales data captures a specific effect different to STAR or $\mathrm{SEM}^{11}$. STEM addresses the special case of either a new-built house $j$ or an improvement/deterioration to house $j$ after its last sale. Both cases impose to all future sales an externality $\varphi^{*}$ that is not fully captured in the own price of house $j$. A simile for the externality imposed by new-built houses can be road traffic congestion, where each extra car imposes external cost to all others on the road. The construction of an extra house affects all other houses in the area improving or deteriorating the current neighborhood quality, as do major house improvements/deteriorations. Even purely from a dwelling density perspective $\varphi^{*}$ is not necessarily negative, as a marginal increase in dwelling density may be negative in some markets/areas and positive in others depending on existing density (Dunse, et al., 2013). Therefore, $\varphi^{*}$ can include a positive agglomeration externality (Thanos and White, 2014) or negative “overcrowding” externality. The only study seen employing STEM in HP is Thanos et al., (2012) and their data is mostly comprised of new-build houses. Even though they do not fully discuss the issue of $\varphi^{*}$, their results suggest that $\varphi^{*}$ is a positive externality in that context.

A crucial methodological issue is the selection of either STAR or STEM, given their differences. The appropriate test for detecting spatial/spatiotemporal dependence is Moran's I and for selecting the model form are the locally robust variations of the Lagrange Multiplier (LM) test (Anselin et al., 1996; Franzese and Hays, 2008). Table 5 presents these tests, where the null hypothesis in Moran's I test of no spatial/spatiotemporal dependence is rejected. The test for STEM is highly significant while the robust STAR test is not. This means that houses prices are not significantly affected by other house prices nearby, but by the developing urban structure of the area and house improvements or the introduction of new-build houses in the urban environment. This makes sense for this specific market, since here has been significant new development in the area during the study period evident by 49.2 percent of the houses sold being newer than 2 years of age. It is also shown that the model selection tests between SAR and SEM are inconclusive, which was also observed in Thanos et al. (2012). 
Given the LM test results we select the STEM. Its structural form is shown in equation 5 and its reduced form in equation 6 :

$$
\begin{gathered}
\mathbf{P}=\mathbf{Z} \mathbf{b}+\varepsilon, \quad \varepsilon=\lambda \mathbf{W} \varepsilon+u, \quad u \sim N\left(0, \sigma^{2} I\right), \\
u=[\mathbf{I}-\lambda \mathbf{W}] \mathbf{P}-[\mathbf{I}-\lambda \mathbf{W}] \mathbf{Z b} .
\end{gathered}
$$

$\mathbf{P}$ is a vector of the house prices ${ }^{12}, \mathbf{Z}$ is a matrix of housing characteristics and $\mathbf{b}$ is a vector of the coefficients. $\lambda$ is the spatiotemporal error coefficient, capturing the spatiotemporal distance weighted $(\mathbf{W})$ error effect $\varepsilon$. Externality $\varphi^{*}$ of the unobserved change in neighborhood quality is captured by $\lambda$.

TABLE 5: Spatial Dependence diagnostics

\begin{tabular}{l|cc|cc}
\hline & \multicolumn{2}{|c|}{ Spatial weight } & \multicolumn{2}{c}{ Spatiotemporal Weight } \\
\hline & Statistic & p-value & Statistic & p-value \\
Moran's I & 7.827 & 0 & 4.940 & 0 \\
Lagrange multiplier: SEM/STEM & 24.389 & 0 & 11.000 & 0.001 \\
Robust Lagrange multiplier: SEM/STEM & 17.476 & 0 & 11.235 & 0.001 \\
Lagrange multiplier: SAR/STAR & 17.938 & 0 & 0.135 & 0.714 \\
Robust Lagrange multiplier: SAR/STAR & 11.024 & 0.001 & 0.370 & 0.543 \\
\hline
\end{tabular}

\section{Post-closure Model Results}

The post-closure HP models' results are found in Table 6. Most of the coefficients are of the expected sign and consistent with the results of the pre-closure model in Thanos et al. (2012), even though our sample size is significantly lower. The spatiotemporal error coefficient $\lambda$ is positive and statistically significant showing a positive unobserved change in neighborhood quality, in agreement with Thanos, et al (2012). Our focus is on aircraft noise and we do not discuss other effects, except to say that the distance to the airport still has a statistically significant positive coefficient even after its closure, which captures the proximity disamenities to an abandoned airport. 
TABLE 6: The Post-closure Models

\begin{tabular}{|c|c|c|c|}
\hline Model & STEM 1 & STEM 2: Alimos & $\begin{array}{l}\text { STEM 3: Alimos } \\
\text { attenuating stigma }\end{array}$ \\
\hline Variable Name & Coef. & Coef. & \\
\hline Total_noise & -0.0026 & & \\
\hline Noise_Alimos & & $-0.0031 * *$ & \\
\hline Noise_No_Alimos & & -0.0024 & -0.0009 \\
\hline Noise_Alimos_y01 & & & $-0.0027 * * *$ \\
\hline Noise_Alimos_y02 & & & -0.0001 \\
\hline sq meters & $0.0053 * * *$ & $0.0054 * * *$ & $0.0054 * * *$ \\
\hline room1_2 & $-0.5728 * * *$ & $-0.5730 * * *$ & $-0.5706 * * *$ \\
\hline room3 & $-0.2429 * * *$ & $-0.2431 * * *$ & $-0.2411 * * *$ \\
\hline room4 & Base & Base & Base \\
\hline room5 & $0.1223 * * *$ & $0.1224 * * *$ & $0.1208 * * *$ \\
\hline room6 & $0.2354 * * *$ & $0.2351 * * *$ & $0.2392 * * *$ \\
\hline room7 & $0.2588 * * *$ & $0.2584 * * *$ & $0.2574 * * *$ \\
\hline House $>10 \mathrm{yr}$ & $-0.0727 * *$ & $-0.0734 * *$ & $-0.0693 * *$ \\
\hline House 6-9yr & -0.0349 & -0.0354 & -0.0331 \\
\hline H_Age_B & Base & Base & Base \\
\hline floors_7-8 & 0.0113 & 0.0098 & 0.0112 \\
\hline floors_4-6 & $0.0942 * * *$ & $0.0935 * * *$ & $0.0930 * * *$ \\
\hline floors $<4$ & Base & Base & Base \\
\hline detached & $0.2241 * * *$ & $0.2243 * * *$ & $0.2245 * * *$ \\
\hline Semi_ter & $-0.0965^{* *}$ & $-0.0971 * *$ & $-0.0948 * *$ \\
\hline flat & Base & Base & Base \\
\hline garage & $0.1080 * * *$ & $0.1083^{* * * *}$ & $0.1089 * * *$ \\
\hline d_parks & $-9.27 \mathrm{E}-05^{* * *}$ & $-9.34 \mathrm{E}-05^{* * *}$ & $-8.86 \mathrm{E}-05^{* * *}$ \\
\hline d_public_serv & $5.37 \mathrm{E}-05 * *$ & $5.46 \mathrm{E}-05^{* * *}$ & $5.32 \mathrm{E}-05^{* *}$ \\
\hline d_plaza & $-1.26 \mathrm{E}-04 * * *$ & $-1.24 \mathrm{E}-04 * * *$ & $-1.29 \mathrm{E}-04 * * *$ \\
\hline d_school & $1.45 \mathrm{E}-04 * * *$ & $1.44 \mathrm{E}-04 * * *$ & $1.51 \mathrm{E}-04 * * *$ \\
\hline d_airport & $9.79 \mathrm{E}-06^{* * *}$ & $9.62 \mathrm{E}-06^{* * *}$ & $8.86 \mathrm{E}-06^{* * *}$ \\
\hline y2001 & $-0.1609 * * *$ & $-0.1601 * * *$ & \\
\hline y2002 & -0.0110 & -0.0101 & \\
\hline y2003 & Base & Base & \\
\hline constant & $12.07 * * *$ & $12.22 * * *$ & $11.95^{* * *}$ \\
\hline$\lambda$ & $0.0183^{* * *}$ & $0.0251^{* * *}$ & $0.01937 * * *$ \\
\hline Wald $\chi^{2}(48)$ & $6315.94 * * *$ & $6317.29 * * *$ & $6277.98 * * *$ \\
\hline Final LL & 147.713 & 147.798 & 145.649 \\
\hline
\end{tabular}


Housing market stigma effects were reviewed in Section 2, but we have not identified any studies on stigma effects relating to transportation noise. The first of the two models reported here (STEM1) includes an aircraft noise variable for the whole area which shows, as expected, no negative effect or stigma. We tested for nonlinearities in stigma values. However, the statistical significance ${ }^{13}$ of the aircraft noise coefficient is not improved even when we use the iterative logsum threshold approach in Section 5 to look at higher levels of noise exposure.

\section{$\underline{\text { Noise stigma in Alimos }}$}

Given that stigma is not attached to isolated observations of high noise exposure, we tested instead whether stigma is attached to certain areas as a whole. Alimos is the obvious choice, given the high noise exposure and the scope to examine the variation of HP noise values there, stressed in section 3. In the STEM2 model (Table 6), the aircraft noise variable is statistically significant only for Alimos. This suggests that everywhere else, except Alimos, the negative effect of aircraft noise disappeared along with the airport closure. The model indicates a house price depreciation of 0.31 percent per dBA in Alimos for aircraft noise exposure that has now ceased.

This is an extraordinary finding, but at the same time it would be unreasonable to expect that this effect would persist indefinitely ${ }^{14}$. Therefore, we introduce interaction variables between Noise_Alimos and the yearly dummies ${ }^{15}$ to STEM3 model. The results in Table 6 show that indeed this effect attenuates after 2001 and only during that year there is a depreciation of 0.27 percent per $\mathrm{dBA}$ in Alimos. The interpretation of this finding is that the negative associations (in the perceptions of buyers and sellers) for "noisy" Alimos, formed over decades of heavy noise exposure, persist during 2001 and dissipate after that. This could be a behavioral effect and/or inefficiencies in that housing market not allowing instantaneous adjustments after the removal of severe noise exposure. We have no way to distinguish between these effects from our current data.

For completeness, we also test if there are any area effects in Alimos prior to the airport closure. The Alimos/No-Alimos interaction variables were inserted to the pre-closure model of Thanos et al. (2012) to test any peculiar area effects. An asymptotic t-test ${ }^{16}$ showed that the aircraft noise depreciation in Alimos is not significantly different at the 95 percent from all other areas in the pre-closure model. 


\section{STIGMA, NONLINEARITIES AND SPATIAL SORTING}

The HP and SC values are converted to a $€ / \mathrm{dBA} /$ year form to facilitate discussion of the similarities, differences and implications and consistency with the sorting process. The price at which the household purchases a property can be considered as the discounted sum of all the future per period rents from the property. Hence, the monetary value of house attributes may be expressed per period, say annually, to be comparable with SC values. Appendix 1 illustrates in detail the approach and assumption of converting NDI to an annual stream.

Figure 1 plots the curve of aircraft noise monetary values from this study over the range of 45 to $75 \mathrm{dBA}$. This curve is very close to linear below $60 \mathrm{dBA}$, with the nonlinearity becoming more pronounced above the 66-68dBA levels. The curves for the monetary values of road traffic noise from Andersson et al. (2010) and Day et al. (2007) are also plotted, as there are no comparable aircraft noise values over such a detailed range of noise exposure levels in the literature. The dotted lines illustrate the linear approximation of the curves. The second stage HP model of Day et al. (2007) produces values that increase linearly with the noise levels. The findings of Andersson et al. (2010) for road traffic noise show monetary noise values per dBA to be less convex (flatter) than our findings. It is stressed that our approach tested independently for nonlinearity without any imposition of a curve shape.

Table 7 presents the results of SC experiments, pre-closure and post-closure HP models. The uncompensated Marshalian HP value is not directly comparable to income compensated welfare values of WTP and WTA from the SC experiment. The range of value estimates from SC experiment in the base category seem to "envelop" aircraft noise value estimates from HP, except in the case of Alimos. The SC WTP and WTA values for Alimos are extremely low. For example, Alimos residents would be willing to pay very little for aircraft noise not to return, about eight times less than the other residents around Hellenikon airport. It is not credible that other factors, such as income differentials, would explain this difference.

Both the HP and SC results are consistent with the sorting process framework. The nonlinear HP noise values capture the higher discount required by the new entrants to the housing market in 
noisier locations. The SC values of current residents in the noisiest location, Alimos, are markedly lower than other areas. There are also negative associations in housing consumers' perceptions that manifest into a localized stigma only in Alimos that endures for the first year after the airport closure.

FIGURE 1: Comparison of the annual ${ }^{\mathrm{a}}$ monetary value ${ }^{\mathrm{b}}(€)$ of one decibel change.

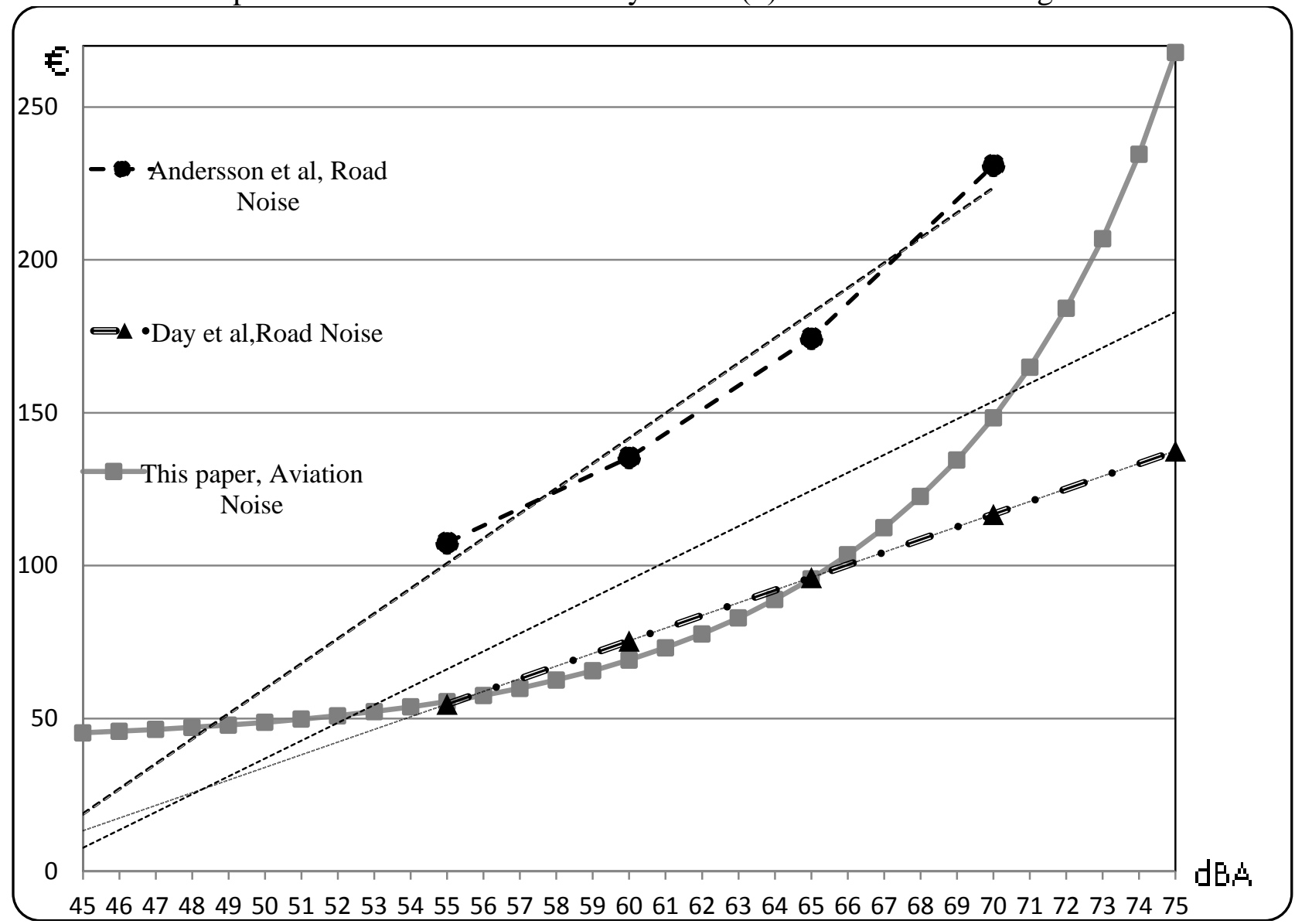

a Andersson et al (2010) NDI results were converted to $€ / \mathrm{dBA} /$ year as indicated in Appendix 1

${ }^{\mathrm{b}}$ All values in this Figure are in €/dBA/year PPP adjusted at 2003 price levels (Eurostat, 2012)

TABLE 7: Monetary Values ${ }^{\mathrm{a}}$ of Aircraft Noise from HP and SC Models

\begin{tabular}{l|r|r|r|r}
\hline & SC WTP & SC WTA & HP pre-closure & $\begin{array}{r}\text { HP post-closure: } \\
\text { Stigma during 2001 }\end{array}$ \\
\hline Other areas & $€ 15.78$ & $€ 96.34$ & $€ 55.52$ & not significant \\
Alimos & $€ 1.94$ & $€ 11.63$ & $€ 50.04$ & $€ 26.09$ \\
\hline
\end{tabular}

a All values in this table are in $€ / \mathrm{dBA} /$ year at 2003 price levels (Eurostat, 2012) 


\section{CONCLUSIONS}

Preference heterogeneity with regard to noise exposure provides the theoretical framework of households sorting across dwelling locations with different exposure levels. This process causes a differentiation in noise values derived from different segments of consumers, according to the spatial distribution of noise exposure. More detailed hypotheses in support of sorting were derived for the direction of HP and SC values changes at differing levels of aviation noise exposure, along with the corollary hypothesis of stigma. Our results are consistent with these hypotheses. In the pre-closure HP models, new housing market entrants were found to require discounts that increased convexly in progressively noisier locations. The SC noise values of current residents in Alimos, a special case with significantly higher long-term aviation noise exposure, are considerably lower than SC values from other areas and HP values in the same area. Alimos is also the only area subject to stigma or unalleviated house price depreciation for the first year after the complete removal of aviation noise, possibly due to enduring negative associations in housing market participants' perceptions and/or inefficiencies in that housing market not allowing instantaneous adjustments after the removal of severe noise exposure.

A state-of-the-art STEM was employed to address the common misspecification in spatial HP studies of ignoring the temporal dimension of spatiotemporal data and violating the arrow of time. The positive and statistically significant spatiotemporal error coefficient captures the unobserved improvement in neighborhood quality that includes the positive externality of adding an extra house in the urban environment.

To the best of our knowledge, this is the first time the theoretical framework of the sorting process has been applied to noise valuation. More importantly, this theoretical framework predicts the divergence between the direction of HP and SC noise values in noisy areas, HP increasing and SC decreasing. Another novelty is the recovery of a local noise stigma for the first time in the literature. This is also the first time that NDI nonlinearities have been explicitly linked to threshold selection and the underlying soundscape. The nonlinearity in aircraft noise monetary values before the airport closure is comprehensively explored by an iterative modeling procedure across a range of noise levels. A flexible log-sum threshold approach is utilized that does not reduce noise variation in cross-sectional data. This approach may be extended to combine noise from multiple 
sources and account for variations in the soundscape of different areas in a more realistic manner to typical cut-off points or thresholds. The NDI ranges from 0.40 to 2.38 per dBA for dwellings exposed to aircraft noise exceeding $45 \mathrm{dBA}$ and $75 \mathrm{dBA}$ respectively, indicating a convex relationship.

These findings have implications for noise valuation and policy. First, low noise value estimates from SC and other types of SP applications should be treated with caution, especially where populations are subject to self-selection pressures as a result of long term noise exposure and sorting. There is a need to assess risks to health of such exposure in such communities. Second, where a constant value per decibel is applied in appraisal noise costs will be under-estimated. This is particularly true of areas with high levels of noise exposure, given the nonlinear depreciation of house prices per $\mathrm{dBA}$ of noise increase. Third, the costs from an environmental externality such as noise may well continue after its complete removal, especially in highly exposed areas.

A few avenues of further research stem from this paper. One could be the extension of this approach to equilibrium sorting models that incorporate changes in the supply side of the housing market and a robust framework for valuing non-marginal changes. The design and application of SP experiments that further test the spatial sorting of noise tolerant households would be interesting, especially if specified to incorporate the nonlinearities in values. Another avenue would be improvements in the specification of log-sum thresholds and studies that combine more noise sources, explicitly taking into account the soundscape of the study areas. 
${ }^{1}$ It is noted that the approaches of formal "equilibrium sorting" models are not followed here due to data constraints.

${ }^{2}$ Along with the typical assumptions of homebuyer rationality, efficient housing markets, no transaction costs and exogenously determined aviation noise.

${ }^{3}$ This is the noise level below which noise is assumed to have no monetary value.

${ }^{4} \mathrm{We}$ use SP as an overarching term to include both SC, contingent valuation, and other types of choice/ranking experiment. It is used when the implications discussed go further than SC and are relevant to all SP type of studies

${ }^{5}$ The test of both coefficients being jointly statistically different from zero is not appropriate. The NDI is a linear combination of two coefficients with different variances and a covariance. The variance of NDI should be estimated to conduct tests of statistical significance (Hole, 2007).

${ }^{6}$ A-weighting is the frequency weighting operating as a close proxy to human auditory sensitivity as a function of frequency (Lee and Fleming 2002).

${ }^{7}$ Equivalent continuous sound pressure level over a fixed time period $\left(\mathrm{L}_{\mathrm{eq}}\right)$, where the evening values (18:00 $-22: 00$ ) are weighted by the addition of $5 \mathrm{dBA}$ (A-weighted decibel), and the night values (22:00 - 06:00) are weighted by the addition of $10 \mathrm{dBA}$

${ }^{8}$ Municipalities of Alimos, Palaio Faliro, Glyfada and Hellenikon

${ }^{9}$ where the hedonic price function of each house includes spatially weighted lagged prices of other houses

${ }^{10}$ Independent and identically distributed

${ }^{11}$ Let us take two house sales, $j$ that precedes house sale $i$. It seems reasonable that the effect $\varphi$ from house $j$ should be in the spatiotemporal error term if it influences house price $i$, but cannot be controlled for by the researcher. However, if $\varphi$ is observed by the buyer of house $i$ and influences its price, it is reasonable to assume it was also observed by the buyer of house $j$ that is the source of $\varphi$. Hence, the effect $\varphi$ has already been captured in the price of house $j$ and this would require a STAR specification capturing a technological spillover. Hence, STEM can only capture own unobserved effects that either did not affect the price of $j$ or took place after the sale of $j$ (and before house sale $i$ ).

${ }^{12}$ Given that the Box-Cox specification is not readily implemented in the presence of spatial dependence (Kim et al., 2003), a semi-log specification is selected.

${ }^{13}$ The z-values for $45 \mathrm{dBA}$ and $65 \mathrm{dBA}$ are 1.65 and 1.85 respectively, not closer to 95 percent level significance than the 55dBA (z: 1.87). The statistical significance drops further above 65dBA.

${ }^{14} \mathrm{We}$ are grateful to the two anonymous referees for pointing this out.

15 We have dropped the yearly dummies due to severe multicollinearity: Variance inflation (VIF) for Noise_Alimos*y2001=122.13; Noise_Alimos*y2002 VIF=75.48; y2001 VIF=121.89; and y2002 $\mathrm{VIF}=74.99$. However, we are confident that "Noise_Alimos*y2001" term does not capture the y2001 dummy effect, if anything these two variables are negatively correlated. The correlation between "y2001" and "Noise_Alimos" is - 0.0857 . We cannot reject the null hypothesis of "y2001" and "Noise_Alimos" being independent (Spearman's rho $=-0.0536$, Prob $>|\mathrm{t}|=0.1365$ )

${ }^{16} t=\left(\beta_{1}-\beta_{2}\right) / \sqrt{\sigma^{2}\left(\beta_{1}\right)+\sigma^{2}\left(\beta_{2}\right)-2 \sigma\left(\beta_{1}, \beta_{2}\right)}=0.98$, where $\beta_{1}$ is the aircraft noise coefficient for Alimos and $\beta_{2}$ is the noise coefficient for all other areas. 


\section{REFERENCES}

Andersson, Henrik, Lina Jonsson, and Mikael Ögren. 2010. "Property Prices and Exposure to Multiple Noise Sources: Hedonic Regression with Road and Railway Noise," Environmental and Resource Economics, 45, 73-89.

Anselin, Luc, Anil K.Bera, Raymond Florax, and Mann J. Yoon. 1996. "Simple Diagnostic Tests for Spatial Dependence," Regional Science and Urban Economics, 26, 77-104.

Arsenio, Elisabete, Abigail L. Bristow, and Mark Wardman. 2006. "Stated Choice Valuations of Traffic Related Noise," Transportation Research D, 11, 15-31.

Bank of Greece. 2007. Monthly Statistical Bulletins. Athens Greece: Economic Research Department, Bank of Greece.

Baranzini, Andrea and José V. Ramirez. 2005. "Paying for Quietness: The Impact of Noise on Geneva Rents," Urban studies, 42, 633-646.

Bateman, Ian J., Ian H. Langford, Munro Alistair, Starmer Chris, and Robert Sugden. 2000. "Estimating Four Hicksian Welfare Measures For A Public Good: A Contingent Valuation Investigation," Land Economics, 76(3), 355-373.

Bateman, Ian J., Brett Day, Iain Lake, and Andrew Lovett. 2001. "The Effect of Road Traffic Noise on Residential Property Values: A Literature Review and Hedonic Pricing Study," Scottish Executive Development Department, Edinburgh, UK.

Bateman, Ian J., Brett Day, and Iain Lake. 2004. "The Valuation Of Transport-Related Noise in Birmingham," Non-technical report to Department for Transport, University of East Anglia, UK. Berglund, Birgitta, Thomas Lindvall, and Dietrich H. Schwela. 1999. Guidelines for Community Noise, Expert Task Force Meeting Guideline Document. Geneva: World Health Organization.

Bjørner, Thomas B., Jacob Kronbak, and Thomas Lundhede. 2003, "Valuation of Noise Reduction-Comparing Results from Hedonic Pricing and Contingent Valuation," $S \emptyset M$ Publication, no. 51. Copenhagen, Denmark: AKF Forlaget.

Brandt, Sebastian and Wolfgang Maennig. 2011. "Road Noise Exposure and Residential Property Prices: Evidence from Hamburg," Transportation Research Part D: Transport and Environment, $16,23-30$. 


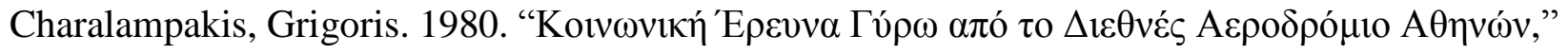

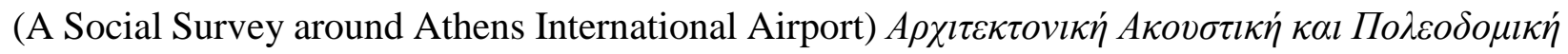

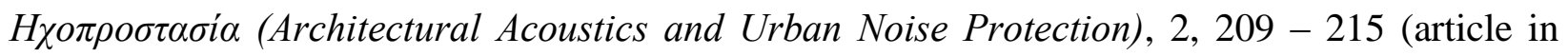
Greek).

Chalermpong, Saksith. 2010. "Impact of Airport Noise on Property Values: Case of Suvarnabhumi International Airport, Bangkok, Thailand," Journal of the Transportation Research Board, 2177, $8-16$.

Cohen, Jeffrey P. and Cletus C. Coughlin. 2008. "Spatial Hedonic Models of Airport Noise, Proximity, and Housing Prices," Journal of Regional Science, 48, 859-878.

Congdon-Hohman, Joshua M. 2013. "The Lasting Effects of Crime: The Relationship of Discovered Methamphetamine Laboratories and Home Values," Regional Science and Urban Economics, 43, 31-41.

Day, Brett, Ian J. Bateman, and Iain Lake. 2007. "Beyond Implicit Prices: Recovering Theoretically Consistent and Transferable Values for Noise Avoidance from a Hedonic Property Price Model," Environmental and Resource Economics, 37, 211-232.

Dale, Larry, James C. Murdoch, Mark A. Thayer, and Paul A. Waddell. 1999. "Do Property Values Rebound from Environmental Stigmas? Evidence from Dallas," Land Economics, 75, 311326.

Dekkers, Jasper E.C. and J. Willemijn van der Straaten. 2009. "Monetary Valuation of Aircraft Noise: A Hedonic Analysis around Amsterdam Airport, Ecological Economics, 68, 2850-2858.

Dubé, Jean, Diègo Legros, Marius Thériault, and François Des Rosiers. 2014. "A spatial Difference-in-Differences Estimator to Evaluate the Effect of Change in Public Mass Transit Systems on House Prices," Transportation Research Part B: Methodological, 64, 24-40.

Dubé, Jean and Diègo Legros. 2013a. "A Spatio-Temporal Measure of Spatial Dependence: An Example Using Real Estate Data," Papers in Regional Science, 92, 19-30.

Dubé, Jean and Diègo Legros. 2013b. "Dealing with Spatial Data Pooled Over Time in Statistical Models," Letters in Spatial and Resource Sciences, 6, 1-18.

Dubé, Jean and Diègo Legros. 2014. "Spatial Econometrics and the Hedonic Pricing Model: What about the Temporal Dimension?" Journal of Property Research.

Dunse, Neil A., Sotirios Thanos, and Glen Bramley. 2013. "Planning Policy, Housing Density and Consumer Preferences," Journal of Property Research, 30, 221-238. 
Eliasson, Jonas, Johanna Lindqvist Dillen, and Jenny Widell. 2002. "Measuring Intrusion Valuations through Stated Preference and Hedonic Prices: A Comparative Study," paper presented at the European Transport Conference, London.

European Environment Agency, 2010. Towards a Resource-Efficient Transport System, TERM 2009: Indicators Tracking Transport and Environment in The European Union, No2/2010. Copenhagen, Denmark: European Environment Agency.

European Council, 2002. "Directive 2002/30/EC of the European Parliament and of the Council of 26 March 2002 on The Establishment of Rules And Procedures with Regard to the Introduction of Noise-Related Operating Restrictions at Community Airports", Official Journal of the European Communities L, 85/40, P. 0040 - 0046.

Eurostat, 2012. Purchasing Power Parities, Price Level Indices and Real Expenditures, unit G6. Luxembourg: The Statistical Office of the European Union.

Faburel Guillaume and Stephane Luchini. 2000. "The Social Cost of Aircraft Noise: The Contingent Valuation Method Applied to Paris-Orly Airport," paper presented at the 29th International Congress and Exhibition on Noise Control Engineering, Nice, France.

Frankel, Marvin. 1988. "Impact of Aircraft Noise on Residential Property Market," Illinois Business Review, 45, 8-13.

Franzese, Jr. Robert J. and Jude C. Hays. 2008. "Empirical Models of Spatial Interdependence," in a J. M. Box-Steffensmeier, H.E. Brady, and D. Collier (eds.), The Oxford Handbook of Political Methodology. Oxford, UK: Oxford University Press, pp. 570-604.

Genescà, Meritxell, Jordi Romeu, Robert Arcos, and Sara Martín. 2013. "Measurement of Aircraft Noise in a High Background Noise Environment Using a Microphone Array," Transportation Research Part D, 18, 70-77.

Hite,Diane, Wen Chern, Fred Hitzhusen, and Alan Randall. 2001. "Property-Value Impacts of an Environmental Disamenity: The Case of Landfills," Journal of Real Estate Finance and Economics, 22(2), 185 - 202.

Hole, Arne Risa. 2007. "A Comparison of Approaches to Estimating Confidence Intervals for Willingness to Pay Measures," Health Economics, 16 (8), 827-840.

Huang, Bo, Wu Bo, and Barry Michael. 2010. "Geographically and Temporally Weighted Regression for Modeling Spatiotemporal Variation in House Prices," International Journal of Geographical Information Science, 24(3), 383-401. 
Kim, Chong Won, Tim T. Phipps, and Luc Anselin. 2003. "Measuring the Benefits of Air Quality Improvement: A Spatial Hedonic Approach," Journal of Environmental Economics and Management, 45, 24-39.

Kuminoff, Nicolai V., V. Kerry Smith, and Christopher Timmins. 2013. "The New Economics of Equilibrium Sorting and Policy Evaluation Using Housing Markets," Journal of Economic Literature, 51(4), 1007-1062.

Lake, Iain R., Andrew Lovett, Ian J. Bateman, and Brett Day. 2000. "Improving Land Compensation Procedures Via GIS And Hedonic Pricing," Environment and Planning C: Government and Policy, 18, $681-696$.

Lake, Iain R., Andrew Lovett, Ian J. Bateman, and Ian H. Langford. 1998. "Modelling Environmental Influences on Property Prices in an Urban Environment," Computers, Environment and Urban Systems, 22, 121-136.

Lee, Cynthia S.Y. and Gregg G. Fleming. 2002. "General Health Effects of Transportation Noise," US Department of Transportation.

McCluskey, Jill J., Gordon C. Rausser. 2003. "Stigmatized Asset Value: Is It Temporary or Long Term?" Review of Economics and Statistics, 85 (2), 276-285.

Miedema, Henk M.E. 2007. "Annoyance Caused By Environmental Noise: Elements for Evidence-Based Noise Policies," Journal of Social Issues, 63, 41-57.

Miedema, Henk M.E., Vos Henk, and Ronald G. de Jong. 2000. "Community Reaction to Aircraft Noise: Time-Of-Day Penalty and Trade off Between Levels of Overflights," Journal of the Acoustical Society of America, 107, 3245-3253.

Nappi-Choulet, Ingrid and Tristan-Pierre Maury. 2009. "A Spatiotemporal Autoregressive Price Index for the Paris Office Property Market," Real Estate Economics, 37(2), 305-340.

Nappi-Choulet, Ingrid and Tristan-Pierre Maury.2011. "A Spatial and Temporal Autoregressive Local Estimation for the Paris Housing Market," Journal of Regional Science, 51(4), 732-750.

Nellthorp, John, Abigail L. Bristow, and Brett Day. 2007. "Introducing Willingness-To-Pay for Noise Changes into Transport Appraisal - An Application of Benefit Transfer," Transport Reviews 27(3) 327-353.

Nelson, Jon P. 2008. "Hedonic Property Value Studies of Transportation Noise: Aircraft and Road Traffic," in a A. Baranzini, J. Ramirez, C. Schaerer, and P. Thalmann (eds.), Hedonic Methods in 
Housing Markets Pricing Environmental Amenities and Segregation. New York, USA: Springer, pp. 55-82.

Nicol, Fergus and Michael Wilson. 2004. "The Effect of Street Dimensions and Traffic Density on the Noise Level and Natural Ventilation Potential in Urban Canyons," Energy and Buildings, $36,423-434$.

Pommerehne, Werner W. 1988. "Measuring the Environmental Benefits: A Comparison of Hedonic Technique and Contingent Valuation," in a D. Bos, M. Rose, and C. Seidl (eds.), Welfare and Efficiency in Public Economics. Berlin: Springer-Verlag, pp. 363-400.

Rich, Jeppe H. and Otto A. Nielsen. 2004. "Assessment of Traffic Noise Impacts," International Journal of Environmental Studies, 61, 19-29.

Salvi, Marco. 2008. "Spatial Estimation of the Impact of Airport Noise on Residential Housing Prices," Swiss Journal of Economics and Statistics, 2008-IV-3, 577-606.

Smith, Tony E. 2009. "Estimation Bias in Spatial Models with Strongly Connected Weight Matrices," Geographical Analysis, 41, 307-332.

Smith, Tony E. and Peggy Wu. 2011. "A Spatio-Temporal Model of Housing Prices Based on Individual Sales Transactions Over Time,” Journal of Geographical Systems, 11(4), 333-355.

Sobotta, Robin R., Heather E. Campbell, and Beverly J. Owens. 2007. "Aviation Noise and Environmental Justice," Journal of Regional Science, 47, 125-154.

Thanos, Sotirios, Abigail L. Bristow, and Mark R. Wardman. 2012. "Theoretically Consistent Temporal Ordering Specification in Spatial Hedonic Pricing Models Applied to the Valuation of Aircraft Noise," Journal of Environmental Economics and Policy, 1, 103-126.

Thanos, Sotirios, Mark R. Wardman, and Abigail L. Bristow. 2011. "Valuing Aircraft Noise: Stated Choice Experiments Reflecting Inter-Temporal Noise Changes from Airport Relocation," Environmental and Resource Economics, 50, 559-583.

Thanos, Sotirios and Michael White. 2014. "Expectation Adjustment in the Housing Market: Insights from the Auction System in Scotland," Housing Studies, 29 (3), 339-361.

Theebe, Marcel A. J. 2004. "Planes, Trains, And Automobiles: The Impact of Traffic Noise on House Prices," Journal of Real Estate Finance and Economics, 28, 209-234.

Thune-Larsen, Harald. 1995. "Flystøyavgifter Basert På Betalingsvillighet", TØI rapport, 289/1995, Institute of Transport Economics, Norwegian Centre for Transport Research, Oslo. 
Tversky, Amos and Daniel Kahneman. 1991. "Loss Aversion in Riskless Choice: A ReferenceDependent Model," The Quarterly Journal of Economics, 106(4), 1039-1061.

Vainio, Matti. 2001. "Comparison of Hedonic Price and Contingent Valuation Methods in the Urban Traffic Noise Context," paper presented at the 2001 International Congress and Exhibition on Noise Control Engineering, The Hague.

Wardman Mark R. and Abigail L. Bristow. 2004. "Traffic Related Noise and Air Quality Valuations: Evidence from Stated Preference Residential Choice Models," Transportation Research D, 9, 1-27.

Weinberger, Marius. 1992. "Gesamtwirtschaftliche Kosten des Lärms in der Bundesrepublik Deutschland," Zeitschrift für Lärmbekämpfung, 39, 91-99.

Wilhelmsson, Mats. 2000. "Impact of traffic Noise on the Values of Single-Family Houses," Journal of Environmental Planning and Management, 43, 799-815.

Yang, Wei and Jian Kang. 2005. "Acoustic Comfort Evaluation in Urban Open Public Spaces," Applied Acoustics, 66, 211-229. 
APPENDIX 1: Converting NDI to annual monetary stream

We follow Bateman et al. (2004) who examine the relationship between rents and house prices. They argue that their findings imply a discount rate that lies between the mortgage rate and the deposit interest rate of the Central Bank. They also assume a certain degree of "myopia" on behalf of house buyers. That is, households are assumed to calculate their discount rate based on current interest rates. Bateman et al. (2004) also argue that it is mathematically convenient and not too unrealistic to assume that the expected life of the property can be taken as infinite.

The central Bank of Greece (2007) 12-month time-deposits rates fell from 10.2 in 1997 and 8.7 in 1999 to 3.3 percent in 2001. The mortgage interest rate fell from 12.6 in 1999 to 6.5 percent in 2001 and it has been around 5 percent after 2002 (Bank of Greece, 2007). There is much variability before 2001, which cannot be captured easily in a single discount rate. The "myopia" assumption of Bateman et al (2004) might not be sufficient in this case, since the public knew well in advance the effects on mortgage, deposit and inflation rates, of Greece entering the Euro-zone. The discount rate of 5 percent is therefore considered more appropriate for calculating annual values. It is not in the middle of the mortgage and the bank deposit rates, but closer to mortgage rate, to account for higher discount rates before 2001 and for "myopia" on the part of house buyers.

Multiplying the discounted annual rent by the noise depreciation, aircraft noise monetary values in the form of $€ / \mathrm{dBA} /$ year are obtained. All values in Tables 7 and Figure 1 are adjusted to 2003 price levels (Eurostat, 2012). The monthly values in Thanos et al. (2011) are converted to annual. 